University of Nebraska - Lincoln

DigitalCommons@University of Nebraska - Lincoln

\title{
Influence of nitrogen growth pressure on the ferromagnetic properties of Cr-doped AIN thin films
}

\author{
Jun Zhang \\ University of Nebraska-Lincoln \\ Xingzhong Li \\ University of Nebraska-Lincoln, xli2@unl.edu \\ B. $\mathrm{Xu}$ \\ University of Nebraska-Lincoln \\ David J. Sellmyer \\ University of Nebraska-Lincoln, dsellmyer@unl.edu
}

Follow this and additional works at: https://digitalcommons.unl.edu/cmrafacpub

Part of the Nanoscience and Nanotechnology Commons

Zhang, Jun; Li, Xingzhong; Xu, B.; and Sellmyer, David J., "Influence of nitrogen growth pressure on the ferromagnetic properties of Cr-doped AIN thin films" (2005). Faculty Publications from Nebraska Center for Materials and Nanoscience. 1.

https://digitalcommons.unl.edu/cmrafacpub/1

This Article is brought to you for free and open access by the Materials and Nanoscience, Nebraska Center for (NCMN) at DigitalCommons@University of Nebraska - Lincoln. It has been accepted for inclusion in Faculty Publications from Nebraska Center for Materials and Nanoscience by an authorized administrator of DigitalCommons@University of Nebraska - Lincoln. 


\title{
Influence of nitrogen growth pressure on the ferromagnetic properties of Cr-doped AIN thin films
}

\author{
Jun Zhang \\ Department of Physics and Astronomy and Center for Materials Research and Analysis, \\ University of Nebraska, Lincoln, Nebraska 68588 \\ X. Z. Li \\ Center for Materials Research and Analysis, University of Nebraska, Lincoln, Nebraska 68588 \\ B. Xu and D. J. Sellmyer ${ }^{\text {a) }}$ \\ Department of Physics and Astronomy and Center for Materials Research and Analysis, \\ University of Nebraska, Lincoln, Nebraska 68588
}

(Received 29 November 2004; accepted 20 April 2005; published online 19 May 2005)

\begin{abstract}
We report the magnetic properties of Cr-doped AIN thin films grown by reactive magnetron sputtering under various nitrogen pressures. Ferromagnetism is observed up to the highest temperature measured, $400 \mathrm{~K}$, and shows strong dependence on the Cr concentration and, especially, the nitrogen growth pressure. By varying the nitrogen pressure during film growth, the magnetic properties of the films can be changed while keeping a constant $\mathrm{Cr}$ concentration. The ferromagnetism is enhanced in the films that were grown at low nitrogen pressures and thus nitrogen deficient, suggesting an important role of defects in the ferromagnetism of this material. (C) 2005 American Institute of Physics. [DOI: 10.1063/1.1940131]
\end{abstract}

There is currently intense interest in ferromagnetic semiconductors (FS), since they hold unique potential for spintronics applications. ${ }^{1,2}$ The most studied system is GaMnAs, but its Curie temperature, $T_{C}$, is far below room temperature. Following theoretical predictions, ${ }^{3}$ many efforts have been made toward FS with high $T_{C}$, and room-temperature ferromagnetism has been observed in doped oxides and nitrides, such as $\mathrm{ZnO}^{4}{ }^{4} \mathrm{TiO}_{2},{ }^{5} \mathrm{SnO}_{2},{ }^{6}$ and $\mathrm{GaN}^{7}$

Recently high-temperature ferromagnetism has also been observed in AlN-based materials, ${ }^{8-13}$ and $T_{C}$ of Cr-doped AlN has been reported to be over $900 \mathrm{~K} .{ }^{12,13}$ Different values of saturation moment were reported in the Cr-doped AlN films fabricated by sputtering, ${ }^{8,12}$ molecular beam epitaxy, ${ }^{9,13}$ and ion implantation, ${ }^{10}$ suggesting that the magnetic properties may be sensitive to the film-growth conditions. Compared to the experimental progress, the theoretical understanding of the high-temperature ferromagnetism is still rather limited. Carrier-mediated ferromagnetism ${ }^{3}$ applied in GaMnAs does not apply to the high-temperature FS systems such as doped $\mathrm{AlN}^{11}$ and $\mathrm{GaN} .{ }^{14}$ More detailed investigations of the effect of film-growth conditions will be helpful for better understanding of the ferromagnetism in these high $T_{C}$ FS.

In this letter we report the effect of nitrogen growth pressure on the ferromagnetism in Cr-doped $\mathrm{AlN}\left(\mathrm{Al}_{1-x} \mathrm{Cr}_{x} \mathrm{~N}_{\mathrm{y}}\right.$, referred as $\mathrm{AlCrN}$ hereafter) thin films grown by reactive magnetron sputtering. Ferromagnetism is observed with $T_{C}$ over $400 \mathrm{~K}$, and it strongly depends on the $\mathrm{Cr}$ concentration and the nitrogen growth pressure. The films grown at lower nitrogen pressures are more deficient in nitrogen, and show larger magnetic moments.

$\mathrm{AlCrN}$ thin films were grown on $\mathrm{Si}$ substrates at ambient temperature by reactive magnetron sputtering of pure $\mathrm{Al}$ and $\mathrm{Cr}$ targets under a mixed $\mathrm{Ar}$ and $\mathrm{N}_{2}$ atmosphere. During

\footnotetext{
a) Author to whom correspondence should be addressed; electronic mail:
} dsellmyer@unl.edu sputtering, the $\mathrm{N}_{2}$ partial pressure was adjusted, while the $\mathrm{Ar}$ partial pressure was fixed at $5 \mathrm{mTorr}$, with the $\mathrm{N}_{2} / \mathrm{Ar}$ pressure ratio $P_{\mathrm{N}} / P_{\mathrm{Ar}}$ varying from 0.5 (low $\mathrm{N}_{2}$ pressure) to 2.0 (high $\mathrm{N}_{2}$ pressure). The film thickness was about $50 \mathrm{~nm}$. The sample compositions were measured by energy dispersive $\mathrm{x}$-ray spectroscopy and x-ray photoemission spectroscopy (XPS). Structure characterization by electron diffraction clearly indicated that the $\mathrm{AlCrN}$ films are polycrystalline with hexagonal wurtzite structure. Transport measurement revealed a semiconducting behavior with resistivity increasing dramatically with decreasing temperature.

Magnetic properties of the $\mathrm{AlCrN}$ thin films were measured with a superconducting quantum interference device magnetometer (Quantum Design, MPMS XL). The diamagnetic background from the Si substrate was subtracted from the total magnetization data. Ferromagnetic behavior was observed up to the highest temperature measured, $400 \mathrm{~K}$, in all films with Cr concentration $x$ ranging from 0.05 to 0.25 . Figure 1 shows a typical magnetization curve at $300 \mathrm{~K}$ of an AlCrN film with $x=0.15$ grown at a $P_{\mathrm{N}} / P_{\mathrm{Ar}}$ of 0.5 . It shows

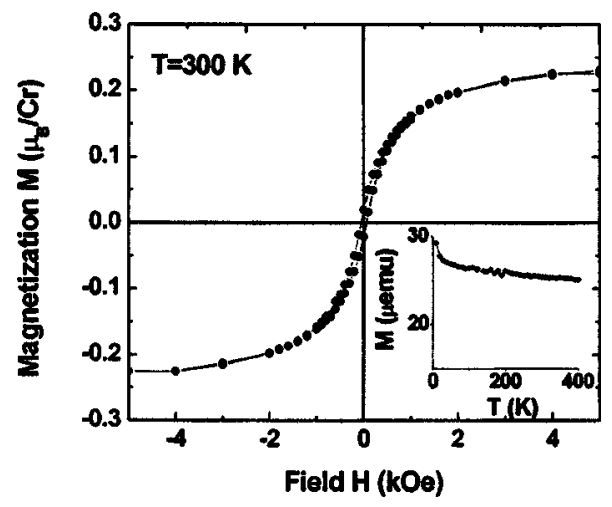

FIG. 1. Hysteresis loop at $300 \mathrm{~K}$ of $\mathrm{AlCrN}$ thin film with $x=0.15$ grown at a $P_{\mathrm{N}} / P_{\mathrm{Ar}}$ of 0.5 . The inset shows the temperature dependence of magnetization for the same sample measured at 5000 Oe. 


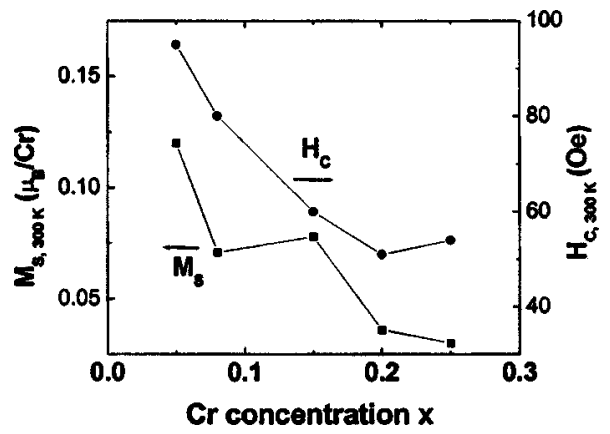

FIG. 2. Cr concentration dependence of the saturation magnetic moment and coercivity at $300 \mathrm{~K}$ for $\mathrm{AlCrN}$ films grown at a $P_{\mathrm{N}} / P_{\mathrm{Ar}}$ of 1.0 .

a well-defined hysteresis loop with a coercivity of 50 Oe and a saturation moment $M_{S}$ of $0.23 \mu_{B} / \mathrm{Cr}$.

The inset of Fig. 1 shows the temperature dependence of the magnetization measured at 5000 Oe for the same sample. With temperature increasing, the magnetization gradually decreases, without any ferromagnetic transition up to the highest temperature measured, $400 \mathrm{~K}$. The tendency of magnetization decreasing suggests that $T_{C}$ is much higher than 400 $\mathrm{K}$. It has been shown that $T_{C}$ of Cr-doped AlN is probably near $1000 \mathrm{~K} \cdot{ }^{12,13}$ No observation of a magnetic transition as the temperature approaches $400 \mathrm{~K}$ indicates absence of the $\mathrm{CrO}_{2}$ phase, which has a $T_{C}$ at $390 \mathrm{~K}$. This is important regarding the origin of the high-temperature ferromagnetism, which has been a concern in AlCrN. ${ }^{9,10,12}$ The absence of the $\mathrm{CrO}_{2}$ phase is further confirmed by XPS measurement. The XPS spectrum of $\mathrm{Cr}$ in the AlCrN films (not shown here) showed a peak for $\mathrm{Cr} 2 p_{3 / 2}$ at $575.6 \mathrm{eV}$, close to the reference value of $575.7 \mathrm{eV}$ for $\mathrm{CrN}$, but definitely different from those of $\mathrm{CrO}_{2}(576.3 \mathrm{eV})$ and $\mathrm{Cr}(574.3 \mathrm{eV})$. These results indicate that no detectable amount of $\mathrm{CrO}_{2}$ or $\mathrm{Cr}$ phase formed in the sample.

The magnetic properties of the AlCrN thin films strongly depend on the $\mathrm{Cr}$ concentration. Figure 2 shows the saturation magnetic moment at $300 \mathrm{~K}, M_{S, 300 \mathrm{~K}}$, and the coercivity at $300 \mathrm{~K}, H_{C, 300 \mathrm{~K}}$, of $\mathrm{AlCrN}$ films grown at a $P_{\mathrm{N}} / P_{\mathrm{Ar}}$ of 1.0 as functions of $\mathrm{Cr}$ concentration. In general, as $\mathrm{Cr}$ concentration increases from 0.05 to 0.25 , both $M_{S, 300 \mathrm{~K}}$ and $H_{C, 300 \mathrm{~K}}$ gradually decrease. In this Cr concentration range, the dependence of saturation magnetic moment on the $\mathrm{Cr}$ concentration is consistent with previous reports, ${ }^{12,13}$ and may indicate enhanced antiferromagnetic coupling at higher Cr concentrations. ${ }^{12}$ The decreasing of coercivity at higher dopant concentration has also been observed in the GaMnAs system. $^{15}$

Notably, the ferromagnetism of $\mathrm{AlCrN}$ films shows strong dependence on the nitrogen growth pressure. The magnetic moment is significantly enhanced in the films grown at relatively low nitrogen pressures. Plotted in Fig. 3 are the hysteresis loops measured at $300 \mathrm{~K}$ for $\mathrm{AlCrN}$ thin films with a fixed $\mathrm{Cr}$ concentration $(x=0.15)$ but grown at different $P_{\mathrm{N}} / P_{\mathrm{Ar}}$. As $P_{\mathrm{N}} / P_{\mathrm{Ar}}$ decreases from 2.0 to 0.5, i.e., nitrogen growth pressure decreases, the saturation magnetization increases significantly, while the coercivity almost does not change. Moreover, the conductivity of the films also increases with reducing the nitrogen growth pressure. The saturation moment and conductivity measured at room temperature $(300 \mathrm{~K})$ are plotted in Fig. 4 as functions of $P_{\mathrm{N}} / P_{\mathrm{Ar}}$. As $P_{\mathrm{N}} / P_{\mathrm{Ar}}$ decreases, both saturation moment and conduc-

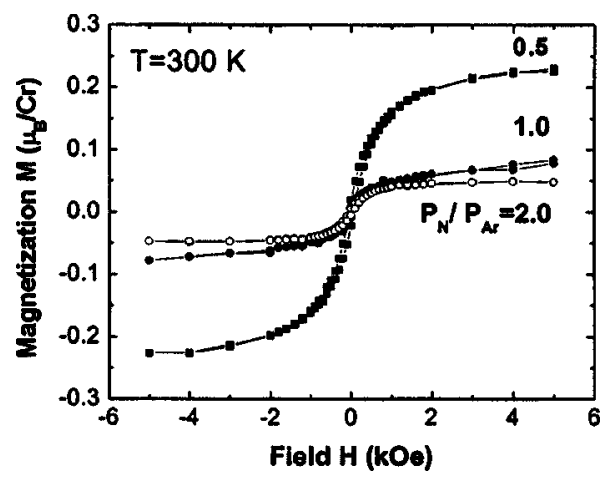

FIG. 3. Hysteresis loops at $300 \mathrm{~K}$ for the $\mathrm{AlCrN}$ thin films $(x=0.15)$ grown at varied $P_{\mathrm{N}} / P_{\mathrm{Ar}}$.

tivity increase, with a large increase occurring as $P_{\mathrm{N}} / P_{\mathrm{Ar}}$ decreases from 1.0 to 0.5 .

The change of transport properties with nitrogen growth pressure has been clarified by measuring nitrogen concentrations in the AlCrN films through XPS analysis. In the film grown at $P_{\mathrm{N}} / P_{\mathrm{Ar}}=2.0$, the ratio of $\mathrm{N} /(\mathrm{Al}, \mathrm{Cr}), y$, is 1.0 ; while in the film grown at $P_{\mathrm{N}} / P_{\mathrm{Ar}}=0.5, y$ is 0.7 , indicating considerable nitrogen deficiencies. Although more accurate techniques would be helpful to detect the absolute value of nitrogen concentrations, considering the $5 \%$ experimental error of XPS, it is reasonable to believe that the AlCrN films grown under lower $\mathrm{N}_{2}$ pressure are more deficient in nitrogen. Nitrogen deficiency could result in defects such as $\mathrm{N}$ vacancies and/or $\mathrm{Al}$ interstitials and produce additional electrons. So the films grown under lower $\mathrm{N}_{2}$ pressure may have more electrons and higher conductivity than those grown under higher $\mathrm{N}_{2}$ pressure. However, in $n$-type wurtzite AlN, the nitrogen vacancy has a high formation energy and is a deep donor, and therefore, this defect cannot make a significant contribution to the $n$-type conduction. ${ }^{16,17}$ Other defects such as Al interstitials are also deep donors. ${ }^{16}$ So, even in nitrogen-deficient $\mathrm{AlCrN}$ films, most defect-generated electrons may localize at or be trapped by the defects, and hence the concentration of itinerant electrons would be very low. This is confirmed by the carrier density data determined from Hall measurements using the van der Pauw configuration. All AlCrN films studied here are $n$ type. The electron concentration and mobility are shown in the inset of Fig. 4 as functions of $P_{\mathrm{N}} / P_{\mathrm{Ar}}$. The electron mobility is in the range of $5-15 \mathrm{~cm}^{2} \mathrm{~V}^{-1} \mathrm{~s}^{-1}$. Although the electron concentration of the films increases as the $P_{\mathrm{N}} / P_{\mathrm{Ar}}$ decreases, the highest concen-

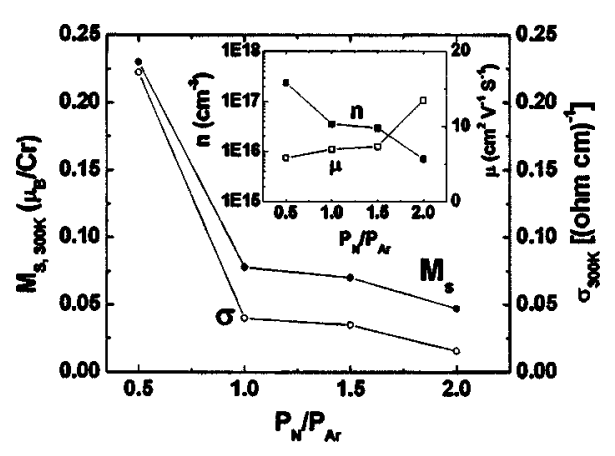

FIG. 4. $P_{\mathrm{N}} / P_{\mathrm{Ar}}$ dependence of saturation magnetic moment $\left(M_{S}\right)$ and conductivity $(\sigma)$ at $300 \mathrm{~K}$ for AlCrN films $(x=0.15)$. Inset: $P_{\mathrm{N}} / P_{\mathrm{Ar}}$ dependence of carrier concentration $(n)$ and mobility $(\mu)$ at $300 \mathrm{~K}$ for AlCrN films $(x$ $=0.15$ ). 
tration is still as low as $10^{17} \mathrm{~cm}^{-3}$. The features of deep defect levels and low carrier densities in the AlCrN system make the carrier-mediated model of ferromagnetism unlikely for this material, ${ }^{8,11-13}$ since this theory requires high concentration of free carriers. ${ }^{3,18,19}$

Although the nitrogen deficiency does not create significant numbers of free carriers, the induced defects and localized carriers may play a role in the ferromagnetism in $\mathrm{AlCrN}$ films. Recently, Kaminski and Das Sarma, ${ }^{20}$ and Coey and co-workers ${ }^{21-23}$ have proposed bound magnetic polaron models for ferromagnetism in poorly conducting semiconductors or oxides. The models associate bound magnetic polarons with localized carriers in extended Bohr orbits, and ferromagnetism is predicted to occur at the polaron percolation threshold. In the model of Coey and co-workers, ${ }^{21-23}$ the bound magnetic polarons consist of electrons surrounding defects, such as oxygen vacancies, which trap electrons and form $\mathrm{F}$ centers, and the Bohr orbital radius of polaron is $\gamma \alpha_{0}$ ( $\alpha_{0}$ is the Bohr radius and $\gamma$ is defined as $\varepsilon m_{e} / m^{*}$, where $\varepsilon$ is the high-frequency dielectric constant, $m_{e}$ is the electron mass, and $m^{*}$ is the electron effective mass ${ }^{22,23}$ ). This bound magnetic polaron model may be applicable to $\mathrm{AlCrN}$, in which the role of nitrogen vacancies in $\mathrm{AlCrN}$ is similar to that of oxygen vacancies in oxides. According to this model, ${ }^{23}$ in the case of wurtzite AlN, the Bohr orbital radius of the associated polaron is about $8.5 \AA$, and the polaron percolation threshold is $0.1 \%$, suggesting that ferromagnetism could occur in $\mathrm{AlCrN}$ with about $0.1 \%$ of the nitrogen sites being vacant. Although they are not expected to occur in very high concentrations, nitrogen vacancies should exist in the nitrogen-deficient $\mathrm{AlCrN}$ films to some extent which could satisfy the percolation threshold. As the nitrogen growth pressure decreases, the nitrogen vacancy concentration should increase, enhancing the polaron percolation and hence the ferromagnetism.

In Co-doped $\mathrm{TiO}_{2}$ system, it was found that reducing oxygen growth pressure created Co clusters, and therefore, increased the magnetic moment and conductivity. ${ }^{24,25}$ But a similar phenomenon involving $\mathrm{Cr}$ clusters in the $\mathrm{AlCrN}$ films appears to be unlikely. Bulk $\mathrm{Cr}$ is antiferromagnetic. A chemical mapping image (not shown here) for $\mathrm{Cr}$ in $\mathrm{AlCrN}$ films obtained by electron energy loss spectroscopy showed a uniform $\mathrm{Cr}$ distribution, ruling out the presence of $\mathrm{Cr}$ clusters with nanometer or larger size. Although large magnetic moment in atomic size $\mathrm{Cr}$ clusters has been predicted, it has not been confirmed experimentally. ${ }^{26}$ Even if this kind of small cluster existed, one would expect to observe superparamagnetism, instead of the ferromagnetism as we show here. In addition, $\mathrm{CrN}$ or $\mathrm{Cr}_{2} \mathrm{~N}$ clusters, if present, would not contribute to the observed ferromagnetism, because $\mathrm{CrN}$ is antiferromagnetic and $\mathrm{Cr}_{2} \mathrm{~N}$ is not ferromagnetic between 85 and $500 \mathrm{~K}^{27}$ Thus, the presence of $\mathrm{Cr}$ clusters cannot be the source of the enhanced ferromagnetism in $\mathrm{AlCrN}$ films grown at low nitrogen pressures.

In summary, ferromagnetism was observed above room temperature in $\mathrm{AlCrN}$ thin films. The magnetic properties of AlCrN films strongly depended on the Cr concentration, and especially, the nitrogen growth pressure. The ferromagnetism was significantly enhanced in the nitrogen-deficient thin films that were grown under lower nitrogen pressure. The results suggest that defects like nitrogen vacancies with their associated bound magnetic polarons may play an important role in the ferromagnetism of $\mathrm{AlCrN}$ films.

This research is supported by ONR, NSF-MRSEC and CMRA.

${ }^{1}$ H. Ohno, Science 281, 951 (1998).

${ }^{2}$ S. A. Wolf, Science 294, 1660 (2001).

${ }^{3}$ T. Dietl, H. Ohno, F. Matsukura, J. Cibert, and D. Ferrand, Science 287, 1019 (2000).

${ }^{4}$ K. Ueda, H. Tabata, and T. Kawai, Appl. Phys. Lett. 79, 988 (2001).

${ }^{5}$ Y. Matsumoto, M. Murakami, T. Shono, T. Hasegawa, T. Fukumura, M. Kawasaki, P. Ahmet, T. Chikyow, S. Koshihara, and H. Koinuma, Science 291, 854 (2001).

${ }^{6}$ S. B. Ogale, R. J. Choudhary, J. P. Buban, S. E. Lofland, S. R. Shinde, S. N. Kale, V. N. Kulkarni, J. Higgins, C. Lanci, J. R. Simpson, N. D. Browning, S. Das Sarma, H. D. Drew, R. L. Greene, and T. Venkatesan, Phys. Rev. Lett. 91, 077205 (2003).

${ }^{7}$ M. L. Reed, N. A. El-Masry, H. H. Stadelmaier, M. K. Ritums, M. J. Reed, C. A. Parker, J. C. Roberts, and S. M. Bedair, Appl. Phys. Lett. 79, 3473 (2001).

${ }^{8}$ S. G. Yang, A. B. Pakhomov, S. T. Hung, and C. Y. Wong, Appl. Phys. Lett. 81, 2418 (2002).

${ }^{9}$ S. Y. Wu, H. X. Liu, L. Gu, R. K. Singh, L. Budd, M. Schilfgaarde, M. R. MaCartney, D. J. Smith, and N. Newman, Appl. Phys. Lett. 82, 3047 (2003).

${ }^{10}$ R. Frazier, J. Stapleton, G. Thaler, C. R. Abernathy, S. J. Pearton, R. Rairigh, J. Kelly, A. F. Hebard, M. L. Nakarmi, K. B. Nam, J. Y. Lin, H. X. Jiang, J. M. Zavada, and R. G. Wilson, J. Appl. Phys. 94, 1592 (2003).

${ }^{11}$ R. Frazier, G. Thaler, M. Overberg, B. Gila, C. R. Abernathy, and S. J. Pearton, Appl. Phys. Lett. 83, 1758 (2003).

${ }^{12}$ D. Kumar, J. Antifakos, M. G. Blamire, and Z. H. Barber, Appl. Phys. Lett. 84, 5004 (2004).

${ }^{13}$ H. X. Liu, S. Y. Wu, R. K. Singh, L. Gu, D. J. Smith, N. Newman, N. R. Dilley, L. Montes, and M. B. Simmonds, Appl. Phys. Lett. 85, 4076 (2004).

${ }^{14}$ T. Graf, M. Gjukic, M. S. Brandt, M. Stutzmann, and O. Ambacher, Appl. Phys. Lett. 81, 5159 (2002).

${ }^{15}$ S. J. Potashnik, K. C. Ku, R. F. Wang, M. B. Stone, N. Samarth, S. Schiffer, and S. H. Chun, J. Appl. Phys. 93, 6784 (2003).

${ }^{16}$ C. Stampfl and C. G. Van de Walle, Phys. Rev. B 65, 155212 (2002).

${ }^{17}$ N. Nepal, K. B. Nam, M. L. Nakarmi, J. Y. Lin, H. X. Jiang, J. M. Zavada, and R. G. Wilson, Appl. Phys. Lett. 84, 1090 (2004).

${ }^{18}$ N. Theodoropoulou, A. F. Hebard, S. N. G. Chu, M. E. Overberg, C. R. Abernathy, S. J. Pearton, R. G. Wilson, and J. M. Zavada, J. Appl. Phys. 91, 7499 (2002).

${ }^{19}$ S. J. Pearton, C. R. Abernathy, G. T. Thaler, R. Frazier, F. Ren, A. F. Hebard, Y. D. Park, D. P. Norton, W. Tang, M. Stavola, J. M. Zavada, and R. G. Wilson, Physica B 340-342, 39 (2003).

${ }^{20}$ A. Kaminski and S. Das Sarma, Phys. Rev. Lett. 88, 247202 (2002).

${ }^{21}$ J. M. D. Coey, A. P. Douvalis, C. B. Fitzgerald, and M. Venkatesan, Appl. Phys. Lett. 84, 1332 (2004).

${ }^{22}$ M. Venkatesan, C. B. Fitzgerald, J. G. Lunney, and J. M. D. Coey, Phys. Rev. Lett. 93, 177206 (2004).

${ }^{23}$ J. M. D. Coey, M. Venkatesan, and C. B. Fitzgerald, Nat. Mater. 4, 173 (2005).

${ }^{24}$ D. H. Kim, J. S. Yang, K. W. Lee, S. D. Bu, D.-W. Kim, T. W. Noh, S.-J. Oh, Y.-W. Kim, J.-S. Chung, H. Tanaka, H. Y. Lee, T. Kawai, J. Y. Won, S. H. Park, and J. C. Lee, J. Appl. Phys. 93, 6125 (2003).

${ }^{25}$ R. J. Kennedy, P. A. Stampe, E. Hu, P. Xiong, S. von Molnar, and Y. Xin, Appl. Phys. Lett. 84, 2832 (2004).

${ }^{26}$ D. C. Douglass, J. P. Bucher, and L. A. Bloomfield, Phys. Rev. B 45, 6341 (1992).

${ }^{27}$ J. D. Browne, P. R. Liddell, R. Street, and T. Mills, Phys. Status Solidi A 1, 715 (1970). 